\title{
Study on Factors Influencing Dysphagia in Elderly Patients with Chronic Obstructive Pulmonary Disease Based on Structural Equation Modeling
}

\author{
RUI ZHANG, HONG YAN LU ${ }^{1 *}$, ZHEN ZHEN WU, LU LU² AND YAN CHANG ${ }^{3}$
}

College of nursing, Ningxia Medical University, No. 1160, Shengli Street, Yinchuan, Ningxia 750004, China, 1Department of Nursing, ${ }^{2}$ Department of General Thoracic Surgery, ${ }^{3}$ Department of Burn Plastic Surgery and Cosmetic, The General Hospital of Ningxia Medical University, No. 804, Shengli Street, Yinchuan City, Ningxia 750004, China

Zhang et al.: Study on Factors Influencing Dysphagia in Elderly Patients with Chronic Obstructive Pulmonary Disease

\begin{abstract}
Dysphagia can occur in elderly patients with chronic obstructive pulmonary disease due to poor coordination between breathing and swallowing. Dysphagia can not only lead to aspiration pneumonia and acute exacerbation of chronic obstructive pulmonary disease, but also increase the risk of death. Previous studies only analyzed the influencing factors, but did not explore the interaction and size of the influencing factors, and there is still a lack of epidemiological investigation of dysphagia in chronic obstructive pulmonary disease patients in China. This study investigated the current situation of dysphagia in patients with chronic obstructive pulmonary disease in elderly chronic obstructive pulmonary disease patients in China, and used structural equation model to explore the direct and indirect effects of influencing factors. From April 2019 to April 2020, 1020 elderly chronic obstructive pulmonary disease patients who met the inclusion and exclusion criteria in the department of respiratory Medicine in 9 tertiary hospitals in Ningxia were selected as study subjects. The data were collected through questionnaires, including general information, chronic obstructive pulmonary disease Assessment Test, Activities of Daily Living, Geriatric Depression Scale, The Mini Nutritional Assessment-Short Form, FRAIL assessment scale, and Water Swallowing Test. On the basis of exploratory factor analysis, Amos was used to construct the initial model in combination with literature and professional knowledge, and the overall fitting evaluation and modification of the model were carried out to construct the final model. The incidence of Dysphagia in patients with chronic obstructive pulmonary disease in elderly chronic obstructive pulmonary disease patients was $19.71 \%$. The modified structural equation model fitted well, and the comprehensive condition of the elderly, smoking condition and comorbidities directly affects the dysphagia (the effect values respectively were $0.372,0.112$ and 0.095$)$.The disease condition not only directly affects dysphagia, but also influences it through the comprehensive condition of the elderly (direct effect 0.109 , indirect effect 0.109, total effect 0.218 ); age factors not only directly affects dysphagia, but also influences it through The disease condition and comprehensive condition of the elderly (direct effect 0.113 , indirect effect 0.183 and total effect 0.296 ). eating condition not only directly affects dysphagia, but also influences it through comprehensive condition of the elderly (direct effect 0.127 , indirect effect 0.074 , total effect 0.201 ). The comprehensive condition of the elderly, smoking status and comorbidities directly affects the swallowing function, and the effect value of comprehensive condition of the elderly on swallowing function is 0.372 . The disease status, age factors and eating status not only directly affect swallowing function, but also indirectly affect it through other factors.
\end{abstract}

Key words: Chronic obstructive pulmonary disease, swallowing function, influencing factors, structural equation model

According to the latest data released by the National Bureau of Statistics in 2018, there are about 240 million people aged 60 and above in China. As the aging of the population becomes more and more serious, the Blue Book on Aging Health: China's Aging Health Report (2018) mentions that healthy aging is the only way for

*Address for correspondence

E-mail: hjm20181106@163.com 
China to actively respond to the aging of the population. Smukalla et al. ${ }^{[1,2]}$ showed that the degeneration of muscle tissues in the oral, pharynx and esophagus in the elderly and degeneration of various functions such as poor age factor and decreased salivary secretion can lead to dysphagia, which has become one of the important factors affecting the health of the elderly.

In addition to age, the disease itself can cause dysphagia. Stroke and chronic obstructive pulmonary disease (COPD) are common diseases that cause dysphagia in the elderly ${ }^{[3]}$. There have been relevant studies on dysphagia in stroke patients both in China and Abroad. The Guidelines for Rehabilitation of Adult Stroke released in 2016 in the United States introduced the process of screening, intervention and management of dysphagia ${ }^{[4]}$. As for dysphagia in COPD patients, no systematic management guidelines have been found.

COPD is a chronic disease characterized by persistent airflow limitation. Studies have shown that dysphagia can result from chronic cough, therapeutic inhalation of bronchodilators, and poor coordination between breathing and swallowing ${ }^{[5-8]}$ Lindroos et al. ${ }^{[9]}$ reported that the incidence of dysphagia in COPD patients in Helsinki, Finland was $11.8 \%$; Gonzalez et al. ${ }^{[10]}$ reported that $78 \%$ of Swedish COPD patients had dysphagia of different degrees. Macri et al. ${ }^{[11]}$ reported that the incidence of dysphagia in British COPD patients was $26.5 \%$. However, there is a lack of epidemiological investigation of dysphagia in COPD patients in China.

Dysphagia can lead to aspiration pneumonia, acute exacerbation of COPD and increase the risk of death $^{[9,12,13]}$. Studies have shown that management of influencing factors can effectively improve patients' swallowing function ${ }^{14}$. Yoshimatsu et al. ${ }^{[3,15,16]}$ using Logistic regression to explore the influence factors of swallowing disorder in that age, the condition of teeth and depression are the influence factors of swallowing disorder and mentioned condition, the condition of disease and chronic diseases will affect its, however, these indicators cannot be directly measured variables (latent variable), conventional regression analysis method is difficult to deal with these factors, At the same time, regression analysis takes whether the independent variable has direct effect on the dependent variable as the estimation goal, and does not consider the internal interaction of the independent variable. Structural equation model is the synthesis of factor analysis and path analysis, which can make up for the deficiency of traditional methods.

Therefore, the purpose of this study was to understand the current situation of dysphagia in elderly COPD patients in China and to use structural equation model to explore the direct and indirect effects of influencing factors, so as to provide a basis for formulating intervention measures for dysphagia.

\section{PATIENTS AND METHODS}

\section{Patients:}

From April 2019 to April 2020, a cross-sectional survey was conducted on COPD patients in 9 level-III hospitals (3 Level-III Level-A hospitals and 6 Level-III Level-B hospitals) in Ningxia.

In this study, COPD patients meeting the following: Inclusion criteria: (1) age $\geq 60$ years, (2) being diagnosed with COPD by a physician, (3) Clear consciousness, No cognitive impairment, able to understand and execute simple instructions of researchers and able to communicate effectively, (4) Informed consent and voluntary participation in this study. Exclusion criteria: (1) patients with other swallowing disorders (stroke, Parkinson's disease, head and neck tumors, esophageal cancer, etc.), (2) those who must fast from water.

\section{Measures:}

Through literature review and combined with clinical practice, relevant factors affecting swallowing disorders in elderly COPD patients were collected, mainly including individual characteristics, chronic disease, overall status, disease status, smoking status and eating status, etc., and a questionnaire was designed on this basis, the researchers conducted a preliminary survey of 48 elderly patients with COPD and improved the questionnaire. The investigator of each hospital shall be trained uniformly (Investigators having worked in respiratory medicine department for $5 \mathrm{y}$ or more, having bachelor's degree and above with the qualification certificate of supervisor nurse, having questionnaire investigation experience). The training contents shall include the research purpose, research contents, questionnaire filling requirements and evaluation methods of Water Swallowing Test (WST); ask the patient about each item of the questionnaire and fill out each item according to the patient's answers. Check if there is any missing item, take it back after checking. General information was collected including sex, age, occupation, marital status, educational level, living style, number of teeth missing, etc.

COPD Assessment Test (CAT) scale used to assess the severity of COPD. Proposed by Jones on the basis of 
the St George Respiratory Questionnaire (SGRQ) in 2009 , it has proven to have good test characteristics in a Chinese population ${ }^{[17]}$ Includes 8 questions. The total score is 40 points, with the total score $<10$ indicating mild illness, $10<$ total score $\leq 20$ indicating moderate illness, $20<$ total score $\leq 30$ indicating serious illness, and $>30$ indicating very serious illness ${ }^{[18-20]}$.

Activities of Daily Living (ADL) are used to evaluate patients' ability of Daily Living Activities. It was first published in 1965 by Dorothy Barthel and Florence Mahone, and it was verified to have good test characteristics among Chinese people ${ }^{[21]}$ includes 10 items. The total score is 100 points, and the evaluation standard is: $81 \sim 100$ points, life completely self-care. $61 \sim 80$ points, mild dysfunction, able to complete daily activities independently; 41 60 points, moderate dysfunction, need help in life $\leq 40$ points, severely dysfunctional or totally dependent, most daily activities cannot be completed or require human care ${ }^{[22]}$.

The Geriatric Depression Scale (GDS) is a measure of Depression in the elderly over the last $1 \mathrm{w}$. Prepared by Brink Equal in 1982, proved to have good test characteristics in The Chinese population ${ }^{[23]}$ includes 30 entries. The total score is 30 and the assessment standard is: $0 \sim 10$ is normal, that is no depression; 11 to 20 are classified as likely to have depressive symptoms; Between 21 and 30 is classified as depression ${ }^{[24]}$.

The Mini Nutritional Assessment-Short Form (MNASF) is designed to evaluate Nutritional status. In 2001, it was proposed by Rubenstein et al. on the basis of Mini Nutritional Assessment (MNA) and verified to have good testing characteristics in Chinese population ${ }^{[25]}$ includes 8 questions. With a total score of 14,12 to 14 is classified as normal nutritional status, 8 to 11 as at risk of malnutrition and 0 to 7 as undernourished ${ }^{[26]}$.

FRAIL assessment scale is used to assess the FRAIL situation of the elderly. It was proposed in 2008 by experts from the International Working Group on Nutrition and Aging and verified to have good testing characteristics in Chinese population ${ }^{[27]}$ includes 5 questions. The assessment criteria were as follows $\geq 3$ could be diagnosed as frailty $<3$ were prophase of asthenia; There were 0 healthy elderly people without weakness $^{[28-30]}$.

Water Swallowing Test (WST) Used for evaluate swallowing function. In 1982, it was proposed by Japanese scholar Toshio Lowa and verified to have good test characteristics in Chinese population ${ }^{[31]}$. Let the patient drink $3 \sim 5 \mathrm{ml}$ of warm boiled water at a time.
If there is no discomfort, ask the patient to drink $30 \mathrm{ml}$ of warm boiled water as usual, and observe the required time and cough. Can be smoothly once swallowed water level for I; Above points 2 times cannot choke to cough to swallow a category II; Can one swallow but there are choke to cough for III level; Above points 2 times to swallow but have a choking cough for IV level; Frequent cough, not all swallowed is Grade V. Evaluation criteria: I level, 5 seconds after drinking $30 \mathrm{ml}$ warm water to normal; I level, more than 5 seconds after drinking $30 \mathrm{ml}$ warm water or II level for suspicious; Abnormal III $\sim$ V level ${ }^{[32]}$.

\section{Ethical considerations:}

This study was approved by the ethics review institution of The General Hospital of Ningxia Medical University (2020-643), which complied with complied with the declaration of Helsinki. Prior to data collection, consent and cooperation were obtained from 9 hospital administrators and departments, and all subjects signed written informed consent.

\section{Data analysis:}

Epidata 3.1 was used for data entry, and SPSS 22.0 was used for data processing and exploratory factor analysis. Measurement data were described by median and quartile, while counting data were described by frequency and percentage. The measurement data of the two groups were compared by mann-Whitney U test, the grading data were compared by Wilcoxon W test, and the counting data were compared by $\chi^{2}$ test. AMOS 25.0 software was used to fit, evaluate and modify the model, establish the final model, and explore the path coefficient among variables. In all analyses, statistical significance was set at $\mathrm{p}<0.05$.

\section{RESULTS AND DISCUSSION}

A total of 1068 questionnaires were issued in this survey, and 1020 valid questionnaires were recovered, with an effective recovery rate of $95.51 \%$. The general information of patients (Table 1). There were 819 patients without dysphagia, accounting for $80.29 \%$; 201 patients of dysphagia, accounting for $19.71 \%$. 1) is the $\chi^{2}$ test; 2) is the $Z$ value.

Through exploratory factor analysis, the common factors were extracted to find the significant variables that affect the latent variables of swallowing disorders in elderly COPD patients. Demographic information, diseaserelated variables, depression status, Weak condition, nutritional status, daily living ability, CAT score, 


\begin{tabular}{|c|c|c|c|c|c|}
\hline Characteristics & $\mathbf{N}$ & $\begin{array}{c}\text { Nondysphagia } \\
\mathrm{n}=819\end{array}$ & $\begin{array}{c}\text { Dysphagia } \\
\mathrm{n}=201\end{array}$ & $x^{2} / z$ & $\mathrm{p}$ \\
\hline \multicolumn{6}{|l|}{ Sex } \\
\hline Male & 622 & $494(60.32)$ & $128(63.68)$ & \multirow{2}{*}{$0.768^{1)}$} & \multirow{2}{*}{0.381} \\
\hline Female & 398 & $325(39.68)$ & $73(36.32)$ & & \\
\hline \multicolumn{6}{|l|}{ Age } \\
\hline $60 \sim 69$ & 399 & $350(42.74)$ & $49(24.38)$ & \multirow{3}{*}{ 25.2991) } & \multirow{3}{*}{$<0.001$} \\
\hline 70 79 & 414 & $320(39.07)$ & $94(46.77)$ & & \\
\hline$\geq 80$ & 207 & $149(18.19)$ & $58(28.86)$ & & \\
\hline Teeth missing & & $2(0,9)$ & $6(0,18)$ & $-3.174^{1)}$ & 0.002 \\
\hline \multicolumn{6}{|l|}{ Can attention to eating } \\
\hline Yes & 846 & $708(86.45)$ & $138(68.66)$ & \multirow{2}{*}{$36.101^{11}$} & \multirow{2}{*}{$<0.001$} \\
\hline No & 174 & $111(13.55)$ & $63(31.34)$ & & \\
\hline \multicolumn{6}{|l|}{ Eating position } \\
\hline Sitting upright & 857 & $713(87.06)$ & $144(71.64)$ & \multirow{2}{*}{$28.565^{1)}$} & \multirow{2}{*}{$<0.001$} \\
\hline half lying position & 163 & $106(12.94)$ & $57(28.36)$ & & \\
\hline \multicolumn{6}{|l|}{ Hypertension } \\
\hline No & 597 & $505(61.66)$ & $92(45.77)$ & \multirow{2}{*}{$16.787^{1)}$} & \multirow{2}{*}{$<0.001$} \\
\hline Yes & 423 & $314(38.34)$ & $109(54.23)$ & & \\
\hline \multicolumn{6}{|l|}{ Diabetes } \\
\hline No & 808 & $676(82.54)$ & $132(65.67)$ & \multirow{2}{*}{$27.891^{11}$} & \multirow{2}{*}{$<0.001$} \\
\hline Yes & 212 & $143(17.46)$ & $69(34.33)$ & & \\
\hline \multicolumn{6}{|l|}{ Coronary heart disease (CHD) } \\
\hline No & 771 & $627(76.56)$ & $144(71.64)$ & \multirow{2}{*}{$2.113^{1)}$} & \multirow{2}{*}{0.146} \\
\hline Yes & 249 & $192(23.44)$ & $57(28.36)$ & & \\
\hline Smoking history & & & & & \\
\hline Never smoking & 572 & $471(57.51)$ & $101(50.25)$ & & \\
\hline To give up smoking & 386 & $303(37.00)$ & $83(41.29)$ & $4.636^{1)}$ & 0.098 \\
\hline smoking & 62 & $45(5.49)$ & $17(8.46)$ & & \\
\hline Cough & & & & & \\
\hline No cough & 106 & $100(12.21)$ & $6(2.99)$ & & \\
\hline Cough is lighter & 657 & $541(66.06)$ & $116(57.71)$ & 34.734 & $<0.001$ \\
\hline Cough is worse than usual & 257 & $178(21.73)$ & $79(39.30)$ & & \\
\hline Sputum & & & & & \\
\hline No sputum & 108 & $107(13.06)$ & $1(0.50)$ & & \\
\hline Sputum is lighter & 630 & $552(67.40)$ & $78(38.80)$ & 144.335 & $<0.001$ \\
\hline Sputum is worse than usual & 282 & $160(19.54)$ & $122(60.70)$ & & \\
\hline Respiratory & & & & & \\
\hline No shortness of breath & 72 & $68(8.30)$ & $4(1.99)$ & & \\
\hline Light shortness of breath & 566 & $500(61.05)$ & $66(32.84)$ & 83637 & $<0,001$ \\
\hline $\begin{array}{l}\text { Shortness of breath is more severe } \\
\text { than usual }\end{array}$ & 382 & $251(30.65)$ & $131(65.17)$ & & \\
\hline CAT & & & & & \\
\hline Slight symptoms & 38 & $36(4.40)$ & $2(0.99)$ & & \\
\hline Medium & 348 & $321(39.19)$ & $27(13.43)$ & & \\
\hline Serious & 528 & $390(47.62)$ & $138(68.66)$ & $-6.421^{2)}$ & $<0.001$ \\
\hline Very serious & 106 & $72(8.79)$ & $34(16.92)$ & & \\
\hline$A D L$ & & & & & \\
\hline Completely independent & 148 & $144(17.58)$ & $4(1.99)$ & & \\
\hline Mild dysfunction & 612 & $523(63.86)$ & $89(44.28)$ & & \\
\hline Moderate dysfunction & 169 & $107(13.06)$ & $62(30.84)$ & 122.864 & $<0.001$ \\
\hline $\begin{array}{l}\text { Severe dysfunction or complete } \\
\text { dependence }\end{array}$ & 91 & $45(5.50)$ & $46(22.89)$ & & \\
\hline 29 & Indian & al of Pharmaceutic & & Spe & sue 3,2021 \\
\hline
\end{tabular}


GDS

There is no depression

Mild depression

Moderate to severe depression

Nutritional condition

Normal nutritional status

Risk of malnutrition

Malnutrition

Frail condition

No weak

Suspicious weak

Weak

\begin{tabular}{lcccc}
433 & $390(47.62)$ & $43(21.39)$ & & \\
464 & $361(44.08)$ & $103(51.24)$ & $76.593^{1)}$ & $<0.001$ \\
123 & $68(8.30)$ & $55(27.37)$ & & \\
& & & & \\
282 & $256(31.26)$ & $26(12.94)$ & & \\
486 & $416(50.79)$ & $70(34.83)$ & $105.043^{1)}$ & $<0.001$ \\
252 & $147(17.95)$ & $105(52.23)$ & & \\
& & & & \\
122 & $115(14.04)$ & $7(3.48)$ & & \\
364 & $303(37.00)$ & $61(30.35)$ & $-4.175^{2)}$ & $<0.001$ \\
534 & $401(48.96)$ & $133(66.17)$ & & \\
\hline
\end{tabular}

TABLE 2: MATRIX AFTER ROTATION OF FACTOR LOAD

\begin{tabular}{lcccccc}
\hline Characteristics & $\begin{array}{c}\text { Common } \\
\text { factor } \mathbf{1}\end{array}$ & $\begin{array}{c}\text { Common } \\
\text { factor 2 }\end{array}$ & $\begin{array}{c}\text { Common } \\
\text { factor 3 }\end{array}$ & $\begin{array}{c}\text { Common } \\
\text { factor 4 }\end{array}$ & $\begin{array}{c}\text { Common } \\
\text { factor 5 }\end{array}$ & $\begin{array}{c}\text { Common } \\
\text { factor 6 }\end{array}$ \\
\hline Frail condition & 0.720 & 0.106 & 0.038 & -0.025 & 0.040 & 0.037 \\
GDS & 0.713 & 0.021 & 0.002 & 0.061 & -0.003 & -0.092 \\
CAT & 0.627 & 0.321 & 0.105 & -0.065 & -0.033 & 0.007 \\
Nutritional condition & 0.621 & -0.011 & 0.040 & 0.114 & 0.036 & 0.208 \\
ADL & 0.614 & 0.201 & 0.041 & 0.124 & -0.087 & 0.278 \\
Sputum situation & 0.048 & 0.833 & -0.003 & 0.047 & 0.050 & 0.104 \\
Cough situation & 0.105 & 0.798 & 0.020 & -0.010 & -0.087 & 0.000 \\
Respiratory condition & 0.309 & 0.689 & 0.094 & -0.069 & 0.089 & 0.013 \\
Diabetes & 0.029 & 0.073 & 0.809 & -0.014 & -0.052 & 0.075 \\
CHD & 0.062 & -0.077 & 0.779 & 0.005 & 0.006 & 0.028 \\
Hypertension & 0.058 & 0.096 & 0.705 & -0.040 & 0.022 & 0.029 \\
Eating position & 0.010 & 0.039 & -0.027 & 0.873 & -0.021 & 0.056 \\
Can attention to eating & 0.135 & -0.061 & 0.002 & 0.853 & 0.017 & -0.002 \\
Smoking history & 0.058 & 0.033 & -0.034 & 0.034 & 0.861 & 0.065 \\
Sex & -0.060 & -0.008 & 0.015 & -0.038 & 0.860 & -0.020 \\
Teeth missing & 0.018 & 0.013 & 0.045 & 0.039 & 0.086 & 0.820 \\
Age & 0.209 & 0.082 & 0.083 & 0.006 & -0.042 & 0.777 \\
\hline
\end{tabular}

and eating status were included in exploratory factor analysis. The results showed that $\mathrm{KMO}=0.726>0.6$, and approximate $2=2318.763(\mathrm{df}=136, \mathrm{p}<0.001)$ in Bartlett spherical test, which met the factor analysis conditions. According to Eigenvalues $>1$ as the standard and combining with the gravel diagram, the number of common factors extracted is 6 . The total variation of interpreted data is $80.1 \%$ (Table 2) for the factor load matrix. According to the variable content corresponding to the common factor, the common factor 1 was defined as the comprehensive condition of the elderly, the common factor 2 as the disease condition, the common factor 3 as the eating condition, the common factor 4 as the smoking condition, the common factor 5 as the comorbidities and the common factor 6 as the age factor.

On the basis of exploratory factor analysis, combined with literature and professional knowledge, building has six latent variables (Comprehensive condition of aging, disease conditions, feeding conditions, smoking status, comorbidities and age factor) and 17 show variables (measurement) of structural equation model, the initial structural equation model of the standardized path diagram (fig. 1).

The fitness of the model was tested according to the initial model path diagram, and it was found that the model could be recognized, but the fitting index was not ideal enough to meet the fitness standard (Table 3). Add the path according to the larger correction index and the actual situation (correction index is greater than 7.882 before correction), and delete the path without statistical significance. Through repeated modification and fitting of the model, a model with good fitting index was finally established (fig. 2).

The comprehensive condition of the elderly directly affects dysphagia, the effect value was 0.372 . The disease condition not only directly affects dysphagia, but also affects it through the pathway: Disease 


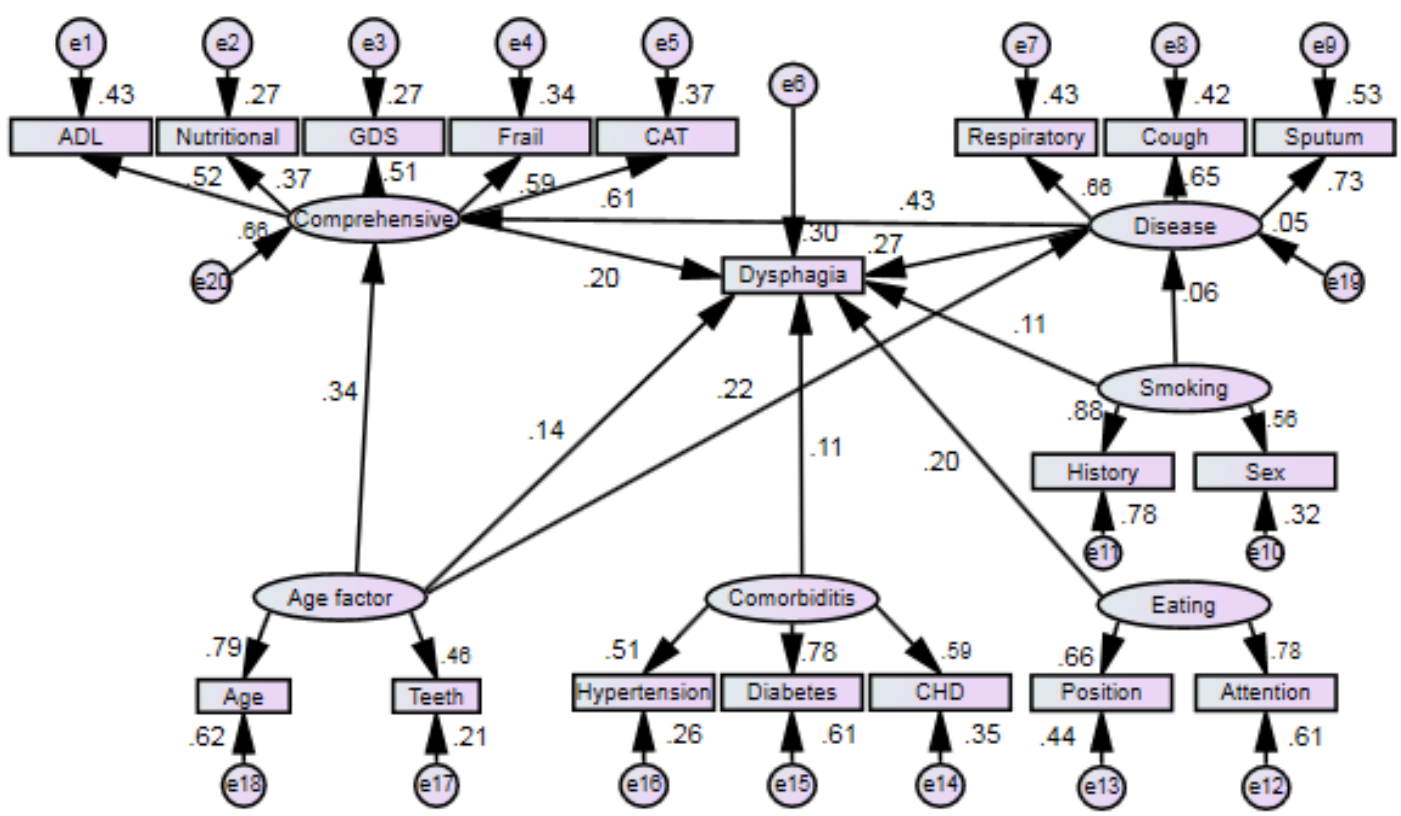

Fig. 1: Structural equation Model of influencing factors of dysphagia in elderly COPD patients (Initial)

TABLE 3: FITTING INDEX OF INFLUENCING FACTORS OF DYSPHAGIA IN ELDERLY COPD PATIENTS

\begin{tabular}{lccccccccc}
\hline Project & $\mathrm{X}^{2} / \mathrm{df}$ & $\mathrm{RMSEA}$ & $\mathrm{NFI}$ & $\mathrm{RFI}$ & $\mathrm{TLI}$ & $\mathrm{CFI}$ & PRATIO & PNFI & PCFI \\
\hline Reference & $1 \sim 2$ & $<0.08$ & $>0.9$ & $>0.9$ & $>0.9$ & $>0.9$ & $>0.5$ & $>0.5$ & $>0.5$ \\
Initial model & 2.548 & 0.047 & 0.872 & 0.844 & 0.899 & 0.917 & 0.824 & 0.718 & 0.755 \\
Final model & 1.610 & 0.029 & 0.923 & 0.901 & 0.960 & 0.969 & 0.784 & 0.724 & 0.760 \\
\hline
\end{tabular}

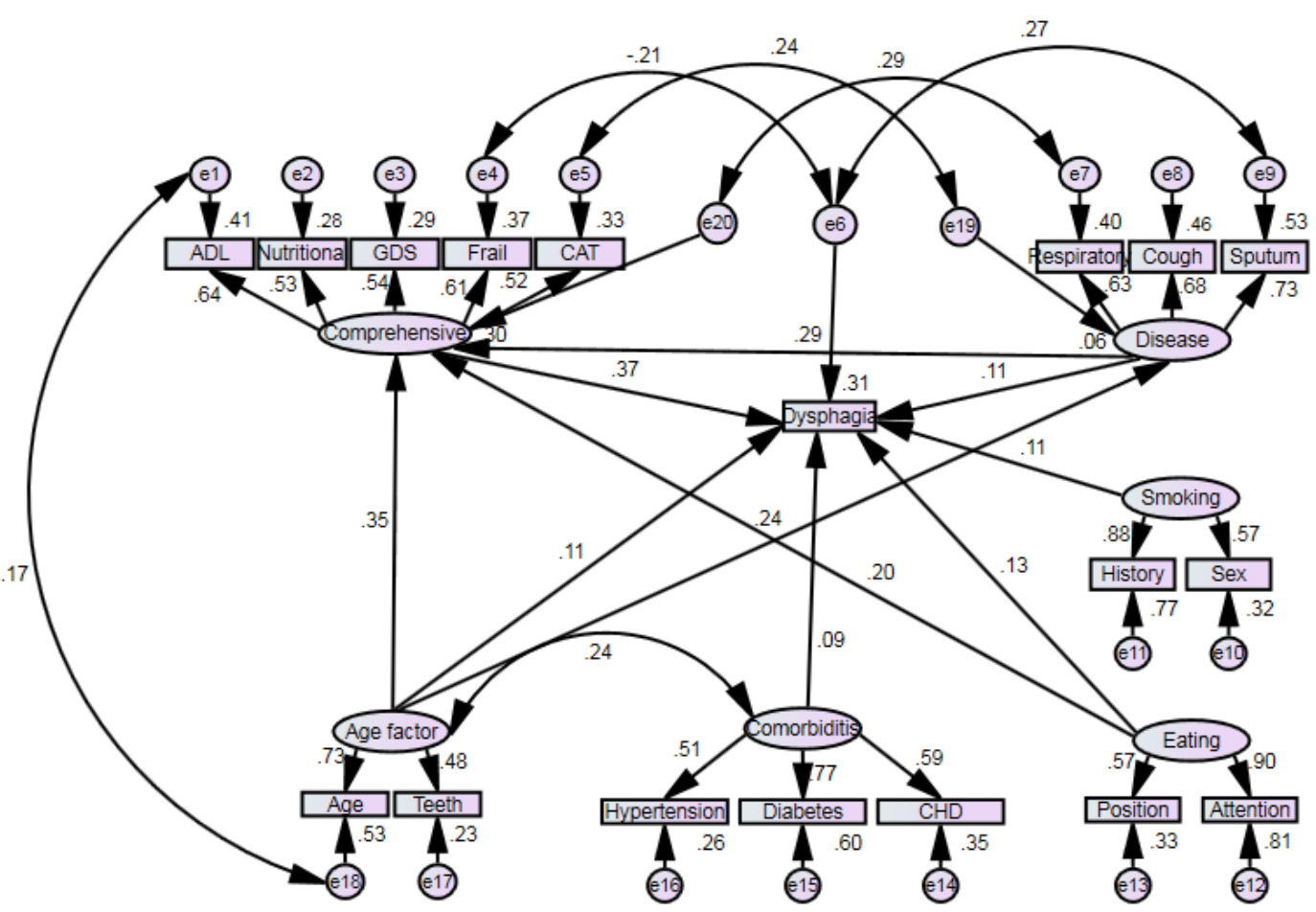

Fig. 2: Structural equation model of influencing factors of Dysphagia in elderly COPD patients (Modified)

condition-The comprehensive condition of the elderly (direct effect 0.109, indirect effect 0.109 and total effect 0.218 ). Smoking condition directly affects dysphagia, the effect value was 0.112. Age factors not only directly affects dysphagia, but also affects it through two pathways: Age factors-Disease condition and Age factors-The comprehensive condition of the elderly (direct effect 0.113 , indirect effect 0.183 and total 
effect 0.296 ). Eating condition not only directly affects dysphagia, but also affects it through the pathway: Eating condition-The comprehensive condition of the elderly (direct effect 0.127 , indirect effect 0.074 , total effect 0.201 ). Comorbidities directly affects dysphagia, the effect value was 0.095 (fig. 2 and Table 4).

Stein et al. ${ }^{[33]}$ evaluated the swallowing function of COPD patients and found that $68.18 \%$ of COPD patients had dysphagia. Coelho et al. ${ }^{[34]}$ found that $21 \%$ of COPD patients had swallowing dysfunction. Gonzalez et al. ${ }^{[10]}$ showed that $65 \%$ of the patients had supervisor symptoms and signs of dysphagia, and $49 \%$ showed objective signs of dysphagia. The results of this study showed that the incidence of dysphagia in elderly COPD patients was $19.71 \%$, meaning that 1 in 5 patients had dysphagia, which is a noteworthy situation. This survey is quite different from other scholars' research reports, which may be related to different screening methods, Gonzalez et al. ${ }^{[10]}$ evaluated and tested the swallowing function of COPD patients through questionnaire survey and the combination of solid test and water test. Coelho et al. ${ }^{[34]}$ used X-ray fluoroscopy to examine the swallowing function of patients. On the other hand, it may be related to the different degree of disease of the included subjects. The severity of the disease in COPD patients would affect their swallowing function. Dysphagia is a common problem in patients with COPD and should be of concern.

The results of this study show that comprehensive conditions of the elderly directly affects the dysphagia, the effect value was 0.372 , That is, the worse the comprehensive condition of the elderly, the greater the likelihood of dysphagia. As a result of chronic degenerative disease, elderly patients generally have poor nutritional status, mental status and activity ability, and are the high incidence of chronic diseases. Based on exploratory factor analysis, Nutritional condition, ADL score, GDS score, Frail condition and CAT score were used as indicators to reflect the comprehensive condition of the elderly. Garand et al. ${ }^{[35]}$ showed that the incidence of dysphagia in COPD patients with malnutrition was relatively high, which was similar to the results of this study, which may be related to the poor nutritional status leading to the weakness of the tongue, hypoesthesia of the upper digestive tract, and weakness of the swallowing muscles, thus causing the impaired swallowing function. In patients with Frail, the glossal muscle strength is weakened and hyoid motor is slowed down, often lead to decreased swallowing efficiency and food residues ${ }^{[36]}$. Cohen et al. ${ }^{[37]}$ showed that the incidence of dysphagia in Non-frail, Pre-frail and Frail inpatients respectively was $2.9 \%, 7.9 \%$ and $16.0 \%(\mathrm{p}<0.001)$, which were similar to the results of this study. Few previous studies have analyzed the Activities of Daily Living as an influencing factor of dysphagia. In this study, it was found that patients with poor ability of daily living were more likely to have swallowing disorder, which may be related to the weak muscle strength of patients with poor self-care ability, affecting the swallowing related muscles. According to the study, the incidence of depression is significantly higher in COPD patients than in non-COPD patients. Swallowing is a complex neural reflex process that is not only dominated by brain consciousness but also by emotional activity, and patients with depression tend to have poor swallowing function ${ }^{[38]}$. In this study, CAT score was considered as a factor affecting swallowing disorder, and the higher the CAT score, the higher the risk of dysphagia.

Dysphagia is not only directly affected by the disease condition, but also indirectly affected by the comprehensive conditions of the elderly. In this study, respiratory, cough and sputum were used as indicators to reflect the disease conditions of patients. In this study, respiratory, cough and sputum were used as indicators to reflect the disease status of patients. Patients with acute exacerbation of COPD showed aggravation of cough, sputum and shortness of breath. On the one hand, progressive hyperinflation of lung and increase of lung volume would occur. On the other hand, the patient's dyspnea worsened, the level of respiratory center drive increased, and the negative chest pressure increased. Therefore, patients with acute

TABLE 4: ANALYSIS OF THE INFLUENCE PATH OF EACH FACTOR IN DYSPHAGIA

\begin{tabular}{lccc}
\hline \multirow{2}{*}{ Variable } & \multicolumn{3}{c}{ Dysphagia } \\
\cline { 2 - 4 } Comprehensive condition of the elderly & Direct effect & Indirect effect & Total effect \\
Disease condition & 0.372 & - & 0.372 \\
Smoking condition & 0.109 & 0.109 & 0.218 \\
Age factors & 0.112 & - & 0.112 \\
Eating condition & 0.113 & 0.183 & 0.296 \\
Comorbidities & 0.127 & 0.074 & 0.201 \\
\hline
\end{tabular}


exacerbation often suffer from swallowing dysfunction due to enlarged lung volume and increased pressure difference between oropharynx and thorax ${ }^{[8]}$. COPD not only causes physical harm to patients, but also affects their mental health. However, there has been no study to investigate whether the disease condition affects swallowing function in elderly patients through their comprehensive conditions. The results of this study suggested that the disease condition has an indirect effect on dysphagia through comprehensive conditions of the elderiy, with an effect value of 0.109.

Smoking condition had a direct effect on dysphagia, the effect value was 0.112 . Smoking history and gender were used as indicators to reflect smoking condition of patients in this study. On the one hand, smoking is significantly associated with acute exacerbation, which aggravates the inflammatory response status of COPD patients. On the other hand smoking patients with laryngeal sensitivity decreased ${ }^{[13,39]}$. Yoshimatsu et al. ${ }^{[16]}$ showed that smoking history was an influential factor in dysphagia. Some research results showed that there were statistically significant differences in the occurrence of dysphagia among patients of different genders, which was consistent with the results of this study. However, Gonzalez et al. ${ }^{[10]}$ indicated that gender had no significant influence on the occurrence of dysphagia. This may be due to the fact that most of the male patients in this study are smokers and have ever smoked, $24 \%$ of the male patients in the study had never smoked, while $85 \%$ of the female patients had never smoked.

Age factors not only directly affects dysphagia, but also indirectly affect them through two pathways of comprehensive conditions of the elderly and disease condition. This study used age and the number of teeth lost as indicators of age factors.

Because of some pathophysiological changes associated with aging, Most of the elderly taste bud atrophy, gland secretion function decline, nerve peripheral receptor function gradually dull, muscle degeneration, pharynx and esophageal peristalsis ability weakened can lead to decreased appetite, active desire to swallow and swallow function decline, these age-related changes make the elderly become the high incidence of dysphagia ${ }^{[1,2]}$. The elderly often suffer from tooth loss due to calcium loss, which will lead to decreased chewing function. Okamoto et al. ${ }^{[15]}$ indicated that the number of tooth loss is positively correlated with the swallowing function. The growth of the age can cause low immunity, cough reflex in patients with weak, sickly coexist and malnutrition, So the age is a risk factor for infection in patients, the bacteria and virus infection is considered to be the COPD patients with acute exacerbation of the most common cause, at the same time as the growth of the age old people each functional degradation, The comprehensive conditions of the elderly is generally poor ${ }^{[40,41]}$. At present, there is lack of relevant study on the influence of age factors on dysphagia through comprehensive conditions of the elderly and disease conditions. The results of this survey show that age factors can indirectly affect dysphagia through comprehensive conditions of the elderly and disease conditions, with an effect value of 0.183 .

The results of this study show that eating condition not only directly affects the occurrence of dysphagia, but also indirectly affects it through the comprehensive conditions of the elderly. This study takes eating position and Can attention to eating as indicators to reflect eating status. The influence of eating position on the occurrence of dysphagia is controversial. Some scholars have showed that in addition to food, oral secretions can also enter the airway and cause dysphagia. Simply change the eating position cannot reduce the occurrence of dysphagia ${ }^{[42]}$. Few studies have reported the effect of intentional to eating on the occurrence of dysphagia. Patients with poor eating conditions often have poor nutritional status leading to poor overall functional status. At present, there is lack of relevant study on the influence of eating conditions on dysphagia through comprehensive conditions of the elderly. The results of this survey show that the indirect effect of eating status on the occurrence of dysphagia through comprehensive conditions of the elderly is 0.074 .

The results of this study show that comorbidities have a direct effect on dysphagia with an effect value of 0.095 . Hypertension, diabetes and coronary heart disease were used as indicators of comorbidities in this study. Bassi et al. ${ }^{[3]}$ showed that the most common comorbidities associated with symptoms and signs of dysphagia include hypertension, diabetes, coronary heart disease, etc. As a special group of elderly people, most of them are associated with basic comorbidities, which make them more vulnerable. Therefore, comorbidities may cause swallowing disorders.

In this study, the incidence of dysphagia in elderly COPD patients was $19.71 \%$. The occurrence of dysphagia was directly affected by the comprehensive condition of the elderly, smoking condition and comorbidities. The disease condition, age factors and 
eating condition; not only directly affects the occurrence of dysphagia, but also have indirect effects on it through other factors. Therefore, health care professionals should not only focus on the direct factors affecting swallowing disorders in COPD patients, but also on the nutritional status, mood changes, and mobility of patients with severe conditions, and take measures to prevent malnutrition, depression, and low mobility in daily life. Older patients should not only focus on their Comprehensive condition, but also take measures to prevent exacerbations in COPD patients. Inability to sit up and focus on food should help patients eat effectively to avoid affecting their Comprehensive condition.

\section{Acknowledgments:}

The authors would like to thank the hospital administrators and investigators for their efforts in this study, as well as all COPD patients who participated in this study, and we also appreciate Associate Professor Lu Hongyan from the General Hospital of Ningxia Medical University for his guidance in this study, RUI. ZHANG and HONG YAN. LU contributed equally to this work.

\section{Disclosure:}

There is no conflict of interest in this study.

\section{REFERENCES}

1. Mun YG, Choi MG, Lim CH, Lee HH, Kang DH, Park JM, et al. Factors affecting endoscopic curative resection of gastric cancer in the population-based screening era. Clin Endosc 2018;51(5):478.

2. Wirth R, Dziewas R, Beck AM, Clave P, Hamdy S, Heppner $\mathrm{HJ}$, et al. Oropharyngeal dysphagia in older persons-from pathophysiology to adequate intervention: a review and summary of an international expert meeting. Clin Interv Aging 2016;11:189-208.

3. Bassi D, Furkim AM, Silva CA, Coelho MS, Rolim MR, Alencar $\mathrm{ML}$, et al. Identification of risk groups for oropharyngeal dysphagia in hospitalized patients in a university hospital. Codas 2014;26(1):17-27.

4. Winstein CJ, Stein J, Arena R, Bates B, Cherney LR, Cramer $\mathrm{SC}$, et al. Guidelines for adult stroke rehabilitation and recovery: a guideline for healthcare professionals from the American Heart Association/American Stroke Association. Stroke 2016;47(6):e98-169.

5. Clayton NA, Carnaby-Mann GD, Peters MJ, Ing AJ. The effect of chronic obstructive pulmonary disease on laryngopharyngeal sensitivity. Ear Nose Throat J 2012;91(9):370-82.

6. Matsuo K, Palmer JB. Anatomy and physiology of feeding and swallowing: normal and abnormal. Phys Med Rehabil Clin N Am 2008;19(4):691-707.

7. Dozier TS, Brodsky MB, Michel Y, Walters Jr BC, Martin Harris B. Coordination of swallowing and respiration in normal sequential cup swallows. Laryngoscope 2006;116(8):1489-93.

8. Kijima M, Isono S, Nishino T. Modulation of swallowing reflex by lung volume changes. Am J Respir Crit Care Med 2000;162(5):1855-8.

9. Lindroos E, Saarela RK, Soini H, Muurinen S, Suominen MH, Pitkala KH. Caregiver-reported swallowing difficulties, malnutrition, and mortality among older people in assisted living facilities. J Nutr Health Aging 2014;18(7):718-22.

10. Lindh MG, Johansson MB, Jennische M, Koyi H. Prevalence of swallowing dysfunction screened in Swedish cohort of COPD patients. Int J Chron Obstruct Pulmon Dis 2017;12:331-7.

11. Macri MR, Marques JM, Santos RS, Furkim AM, Melek I, Rispoli D, et al. Clinical and fiberoptic endoscopic assessment of swallowing in patients with chronic obstructive pulmonary disease. Int Arch Otorhinolaryngol 2013;17(3):274-8.

12. Cabré M, Serra-Prat M, Force LL, Almirall J, Palomera E, Clavé P. Oropharyngeal dysphagia is a risk factor for readmission for pneumonia in the very elderly persons: observational prospective study. J Gerontol A Biol Sci Med Sci 2014;69(3):330-7.

13. Steidl E, Ribeiro CS, Gonçalves BF, Fernandes N, Antunes $\mathrm{V}$, Mancopes R. Relationship between dysphagia and exacerbations in chronic obstructive pulmonary disease: a literature review. Int Arch Otorhinolaryngol 2015;19(1):74-9.

14. McKinstry A, Tranter M, Sweeney J. Outcomes of dysphagia intervention in a pulmonary rehabilitation program. Dysphagia 2010;25(2):104-11.

15. Okamoto N, Morikawa M, Yanagi M, Amano N, Tomioka K, Hazaki $\mathrm{K}$, et al. Association of tooth loss with development of swallowing problems in community-dwelling independent elderly population: the Fujiwara-kyo study. J Gerontol A Biol Sci Med Sci 2015;70(12):1548-54.

16. Yoshimatsu Y, Tobino K, Sueyasu T, Nishizawa S, Ko Y, Yasuda $\mathrm{M}$, et al. Repetitive saliva swallowing test predicts COPD exacerbation. Int J Chron Obstruct Pulmon Dis 2019;14:2777.

17. Xu RX. Application of CAT Scales in patients with Chronic Pulmonary Disease. Chin Foreign Med 2017;36(26):56-8.

18. Silva GP, Morano MT, Viana CM, Magalhaes CB, Pereira ED. Portuguese-language version of the COPD Assessment Test: validation for use in Brazil. J Bras Pneumol 2013;39(4):402-8.

19. Jones PW, Harding G, Berry P, Wiklund I, Chen WH, Leidy NK. Development and first validation of the COPD Assessment Test. Eur Respir J 2009;34(3):648-54.

20. Dugan D, Walker R, Monroe DA. The effects of a 9-week program of aerobic and upper body exercise on the maximal voluntary ventilation of chronic obstructive pulmonary disease patients. J Cardiopulm Rehabil 1995;15(2):130-3.

21. Guo YF, Lin BL, Mei YX. Research progress on assessment tools for activities of daily living in stroke patients in China and abroad. Nursing Res 2019;33(22):3884-8.

22. Fuino M, Rudnytskyi I, Wagner J. On the characteristics of reporting ADL limitations and formal LTC usage across Europe. Eur Actuar J 2020;10(2):557-97.

23. Zhang $\mathrm{H}, \mathrm{Xu}$ WT, Dai B. Reliability and validity of geriatric Depression Scale in sichuan elderly. Chin J Gerontol 2016;36 (14):3548-50.

24. Robinson AC, Roncaroli F, Davidson YS, Minshull J, Heal C, Montaldi D, et al. Mid to late-life scores of depression in the cognitively healthy are associated with cognitive status and Alzheimer's disease pathology at death. Int J Geriatr Psychiatry; 2020.

25. Zhigang X, Wang Y, Yu J. MON-LB324: Application of NRS2002 and MNA to Screen Nutritional Risk in Elderly Patients in a Chinese University Hospital. Clin Nutr 2017;36:S299.

26. Verlaan S, Aspray TJ, Bauer JM, Cederholm T, Hemsworth J, 
Hill TR, et al. Nutritional status, body composition, and quality of life in community-dwelling sarcopenic and non-sarcopenic older adults: A case-control study. Clini Nutr 2017;36(1):26774.

27. Hou P, Xue HP, Li YN. Performance of the FRAIL Scale in Screening Frailty among Elderly Patients with Coronary Heart Disease. Chin General Pract 2019;22(09):1052-6.

28. Valdatta L, Perletti G, Maggiulli F, Tamborini F, Pellegatta I, Cherubino M. FRAIL scale as a predictor of complications and mortality in older patients undergoing reconstructive surgery for non-melanoma skin cancer. Oncol lett 2019;17(1):263-9.

29. Dent E, Kowal P, Hoogendijk EO. Frailty measurement in research and clinical practice: a review. Eur J Int Med 2016;31:3-10.

30. Van Kan GA, Rolland Y, Bergman H, Morley JE, Kritchevsky SB, Vellas B. The IANA Task Force on frailty assessment of older people in clinical practice. J Nutr Health Aging 2008;12(1):29-37.

31. Han R. Progress in the study of dysphagia after stroke. Anhui Med 2009;30(12):1381-6.

32. Yoshimatsu Y, Tobino K, Sueyasu T, Nishizawa S, Ko Y, Yasuda $\mathrm{M}$, et al. Repetitive saliva swallowing test predicts COPD exacerbation. Int J Chron Obstruct Pulmon Dis 2019;14:2777.

33. Stein M, Williams AJ, Grossman F, Weinberg AS, Zuckerbraun L. Cricopharyngeal dysfunction in chronic obstructive pulmonary disease. Chest 1990;97(2):347-52.

34. Coelho CA. Preliminary findings on the nature of dysphagia in patients with chronic obstructive pulmonary disease. Dysphagia 1987;2(1):28-31.

35. Garand KL, Strange C, Paoletti L, Hopkins-Rossabi T, MartinHarris B. Oropharyngeal swallow physiology and swallowingrelated quality of life in underweight patients with concomitant advanced chronic obstructive pulmonary disease. Int J Chron Obstruct Pulmon Dis 2018;13:2663.

36. Yamanashi H, Shimizu Y, Higashi M, Koyamatsu J, Sato S, Nagayoshi $\mathrm{M}$, et al. Validity of maximum isometric tongue pressure as a screening test for physical frailty: Cross-sectional study of Japanese community-dwelling older adults. Geriatr Gerontol Int 2018;18(2):240-9.

37. Cohen SM, Lekan D, Risoli T, Lee HJ, Misono S, Whitson HE, et al. Association Between Dysphagia and Inpatient Outcomes Across Frailty Level Among Patients $\geq 50$ y of Age. Dysphagia 2020;35(5):787-97.

38. Mokhlesi B. Clinical implications of gastroesophageal reflux disease and swallowing dysfunction in COPD. Am J Respir Med 2003;2(2):117-21.

39. Clayton NA, Carnaby GD, Peters MJ, Ing AJ. Impaired laryngopharyngeal sensitivity in patients with COPD: The association with swallow function. Int J Speech Lang Pathol 2014;16(6):615-23.

40. Woodhead M, Blasi F, Ewig S, Garau J, Huchon G, Ieven $\mathrm{M}$, et al. Guidelines for the management of adult lower respiratory tract infections-Full version. Clin Microbiol Infect 2011;17:E1-59.

41. Feng Y, He LX, Cai BQ, Wen FQ, Chen BY, Mangunnegoro $\mathrm{H}$, et al. Spectrum and antimicrobial resistance of common pathogenic bacteria isolated from patients with acute exacerbation of chronic obstructive pulmonary disease in mainland of China. Chin Med J 2013;126(12):2207-14.

42. Shaker RE, Li Q, Ren JU, Townsend WF, Dodds WJ, Martin BJ, et al. Coordination of deglutition and phases of respiration: effect of aging, tachypnea, bolus volume, and chronic obstructive pulmonary disease. Am J Physiol 1992;263(5):G750-5.

This is an open access article distributed under the terms of the Creative Commons Attribution-NonCommercial-ShareAlike 3.0 License, which allows others to remix, tweak, and build upon the work non-commercially, as long as the author is credited and the new creations are licensed under the identical terms

This article was originally published in a special issue, "Evolutionary Strategies in Biomedical Research and Pharmaceutical Sciences" Indian J Pharm Sci 2020:83(3) Spl issue;26-35 